\title{
Observed vs. predicted variability in non-algal suspended particulate matter concentration in the English Channel in relation to tides and waves
}

\author{
Aurélie Rivier ${ }^{\mathrm{a}, \mathrm{b},{ }^{*}, \text { Francis Gohin }^{\mathrm{a}} \text {, Philippe Bryère }}{ }^{\mathrm{c}}$, Caroline Petus $^{\mathrm{a}}$, Nicolas Guillou ${ }^{\mathrm{b}}$ \\ and Georges Chapalain ${ }^{b}$
}

\footnotetext{
a IFREMER, Laboratoire d'écologie pélagique, DYNECO PELAGOS, BP 70, 29280 Plouzané, France

${ }^{b}$ Centre d'Etudes Techniques Maritimes et Fluviales (CETMEF), Laboratoire de Génie Côtier et Environnement (LGCE), 155 rue Pierre Bouguer, Technopôle Brest Iroise BP 5, 29280 Plouzané, France

${ }^{c}$ ACRI, 40 Quai de la douane, 29200 Brest, France
}

\author{
*: Corresponding author : Aurélie Rivier, email address : Tel.: +33-2-98224040 ; Fax:+33-2-98224548 \\ email address : aurelie.rivier@ifremer.fr
}

\begin{abstract}
:
The study of water clarity is essential to understand variability in biological production, particularly in coastal seas. The spatial and temporal variability of non-algal suspended particulate matter (SPM) in surface waters of the English Channel was investigated and related to local forcing by means of a large satellite dataset covering the study area with a spatial resolution of $1.2 \mathrm{~km}$ and a daily temporal resolution. This analysed dataset is a time series of non-algal SPM images derived from MODIS and MERIS remote-sensing reflectance by application of an IFREMER semi-analytical algorithm over the period 2003-2009. In a first step, the variability of time series of MODIS images was analysed through temporal autocorrelation functions. Then, non-algal SPM concentrations were assessed in terms of site-specific explanatory variables such as tides, wind-generated surface-gravity wave amplitudes and chlorophyll-a (Chl-a), based on three statistical models with fitting parameters calibrated on a dataset of merged MERIS/MODIS images gathered from 2007 to 2009 over the whole English Channel. Correlogram analysis and the first model highlight the local patterns of the influence of the tide, especially the neap-spring cycle, on non-algal surface SPM. Its effect is particularly strong in the central and eastern English Channel and in the western coastal areas. The second model shows that waves prevail as driver at the entrance of the English Channel. The most sophisticated of the three statistical models, although involving only three explanatory variables-the tide, waves and $\mathrm{Chl}$-a -is able to estimate non-algal surface SPM with a coefficient of determination reaching $70 \%$ at many locations.
\end{abstract}




\section{Introduction}

Water clarity plays a fundamental role in coastal ecosystem functioning by determining the amount of light available in the water column for primary production. In coastal temperate European waters, this effect on photosynthesis is particularly evident in winter and at the beginning of spring, when light is limiting (Huret et al. 2007). As water clarity in the eutrophic layer is strongly controlled by non-algal suspended particulate matter (SPM) concentration at the sea surface, a better knowledge of the spatiotemporal variability of this key SPM component is required. Prior to the setup and evaluation of a new three-dimensional hydrosedimentary model currently being developed for the English Channel, the present study focuses on analyses of non-algal SPM fluctuations derived from satellite reflectance.

The English Channel (see Fig. 1a for location) is a shallow water environment with strong tides and currents commonly reaching velocities of 1-1.5 m/s, and even exceeding $2 \mathrm{~m} / \mathrm{s}$ in the central cross-section between the Isle of Wight and the Cotentin Peninsula (Salomon and Breton 1993). These currents are associated with distinct dispersion and retention characteristics particularly in the vicinity of capes and islands, leading to complex surface SPM and chlorophyll-a (Chl-a) patterns which are strikingly visible from space (Ménesguen and Gohin 2006). English Channel waters are likely to be influenced by strong tidal stirring throughout the year, as observed also in the adjacent Irish Sea (Bowers et al. 1998). In addition, these waters are affected by seasonal fluctuations in bottom shear stress and turbulence due to wind-generated surface-gravity waves. These effects of waves, particularly important at the western entrance of the Channel, may induce significant sediment resuspension throughout the water column (van der Molen et al. 2009).

Observations of SPM concentrations can be conducted from aboard research vessels (e.g. Velegrakis et al. 1997, 1999 for the English Channel) and, increasingly, from space. Sea surface SPM concentration can be derived from satellite reflectance by means of the 
backscattering coefficient, an inherent optical property related to the size, composition and Nevertheless, data obtained by ocean colour remote sensing seldom fully cover whole areas over longer periods of time.

Bearing such information gaps in mind, an analysis of raw MODIS satellite data (derived from level 2 data) combined with merged MERIS/MODIS non-algal SPM images provided by the Ocean Colour TAC (Thematic Application Facility) of MyOcean has been performed here for the English Channel. This merged dataset consists of fields of non-algal surface SPM concentrations interpolated with a kriging method (Saulquin et al. 2011) for the period 20072009. The objectives of the present study are investigate the potential impact of the neapspring cycle on resuspension of sediments through correlogram analysis and to evaluate the control of non-algal SPM spatiotemporal variability by regional forcing (tides, waves and seasons) by means of three simple statistical models based on multi-regression analysis.

$<$ heading $1>$ Materials and methods

$<$ heading $2>$ Remote sensing data $<$ heading3 $>$ Raw MODIS images

MODIS AQUA L2 satellite data (incorporating standard atmospheric corrections) are available with a resolution of $1.2 \mathrm{~km}$ at high temporal frequency (daily), and allow the monitoring of the English Channel since 2002. They provide a snapshot of ocean colour between about 11:00 a.m. and 2:00 p.m. local time. Non-algal SPM concentrations were obtained from these data using the IFREMER semi-analytical algorithm (Gohin et al. 2005). Non-algal SPM is defined as the difference between total SPM and phytoplankton biomass, the latter derived from Chl-a. It incorporates mainly mineral SPM and smaller amounts of organic SPM not related to living phytoplankton. This method to derive non-algal SPM from remote-sensing reflectance is based on the inversion of a simplified equation of radiative transfer, assuming that chlorophyll concentration is known. This algorithm, built on the backscattering coefficients at 550 and $670 \mathrm{~nm}$, was recently modified and applied in Petus et al. (2010) to the Adour plume. The initial algorithm (Gohin et al. 2005), which uses only the 550 channel to estimate non-algal SPM concentration, performed relatively well for the moderately turbid waters of the Bay of Biscay but underestimated non-algal SPM in the most turbid areas of river plumes. The method currently used for providing the MyOcean SPM products for the IBI (Ireland, Biscay, Iberia) region consists in switching from the $550 \mathrm{~nm}$ channel to $670 \mathrm{~nm}$ when the SPM concentration is higher than $4 \mathrm{mg} / \mathrm{l}$. The method has been 
applied to both MODIS and MERIS images and has given satisfactory results when comparing the statistics (year average, 90th percentile, mean annual cycles) of satellitederived non-algal SPM and in situ measurements at coastal stations (Gohin 2011)). The satellite-derived information was also found to be in agreement with maps of total suspended matter in the English Channel and southern North Sea published by Nechad et al. (2010).

$<$ heading3 $>$ Interpolated MODIS/MERIS data

Clouds may restrict satellite coverage in the visible and infrared wavelengths, leading to data gaps. This would be problematic for in-depth analyses of temporal variability, which require an essentially continuous SPM signal. Saulquin et al. (2011) solved this problem for Chl-a by means of spatiotemporal interpolation based on kriging of ocean colour data. The kriging procedure takes into account the available images 5 days before and after the processed day. This method has been adapted here to non-algal SPM from MODIS and MERIS images of the English Channel from 2007 to 2009.

$<$ heading3 $>$ Monthly MODIS climatologies

Monthly climatologies of non-algal SPM and Chl-a were derived from daily MODIS reflectance for the period 2003-2009, processed by means of the IFREMER coastal algorithm (Gohin et al. 2002, 2005). Figure 1 displays a selection of monthly SPM images exhibiting seasonal variations in non-algal SPM concentrations, with maximum values in winter (Fig. 1a) and minimum values in summer (Fig. 1c). At each location, the daily mean concentrations of non-algal SPM and Chl-a were obtained from temporal linear interpolation of monthly averages attributed arbitrarily to the 15 th of each month. In one of the statistical models tested in this study (cf. below), mean Chl-a is evaluated as representative of seasonal forcing on SPM dynamics. Climatologies of Chl-a published by Gohin (2011) show an increase of Chl-a in early March in the eastern English Channel and later in the central part of the Channel (May). In the western English Channel waters the maximum of Chl-a is observed in June and July following the settling of stratification in the region (Vanhoutte-Brunier et al. 2008).

$<$ heading2 $>$ Physical parameters

$<$ heading3 $>$ Tides

The SHOM (Service Hydrographique et Océanographique de la Marine) tidal coefficient was chosen as being representative of tidal influence. Based on the tidal amplitude calculated at 
Brest, the tidal coefficient provides a good indication of the tidal range in the English Channel. This parameter enables easy identification of the neap-spring cycle, and varies between 20 (neap tide minimum) and 120 (spring tide maximum).

$<$ heading $3>$ Waves

Waves are represented by their significant height Hs. In this study, they were computed by means of the WW3 model developed by Fabrice Ardhuin and provided by the IOWAGA and PREVIMER programs (Tolman 2008; Ardhuin et al. 2010).

$<$ heading2 $>$ Correlogram analysis of raw satellite images

The first objective was to assess the expected impact of tidal activity on large-scale sediment resuspension. Indeed, both semi-diurnal and neap-spring tidal cycles are known to be important in this respect in the study region (e.g. Lafite et al. 2000). Because the temporal resolution of ocean colour data is insufficiently high to encompass semi-diurnal and, for that matter, also diurnal signatures (cf. Neukermans et al. 2009), this work focuses on evaluating the fortnightly neap-spring cycle based on temporal correlogram calculations of non-algal SPM values extracted from raw MODIS images over the period 2003-2009. Autocorrelation functions $C$ were calculated every 30 pixels in rows and columns on the satellite images (corresponding to a spatial resolution of $36 \mathrm{~km}$ ), using the equation:

$$
C(\Delta d, x, y)=\frac{E\{[\operatorname{SPM}(d+\Delta d, x, y)-\overline{\operatorname{SPM}(x, y)}] \times[\operatorname{SPM}(d, x, y)-\overline{\operatorname{SPM}(x, y)}]\}}{\operatorname{Var}_{\mathrm{d}}[\operatorname{SPM}(d, x, y)]}
$$

where $d$ is time, $x$ and $y$ the west-east and south-north spatial coordinates, $\overline{\operatorname{SPM}(x, y)}$ the temporal average of non-algal SPM, $E$ the expected value operator, and $\operatorname{Var}_{d}$ the temporal variance.

A cluster analysis was performed using the Kmean algorithm (Bow 1984) implemented in the program PAST (Hammer et al. 2001) to classify the computed correlogram functions in four classes depending on the shape of the correlogram and, more precisely, on the strength of the 14-day periodicity.

$<$ heading2 $>$ Statistical models applied to interpolated MODIS/MERIS images The second objective was to quantify the site-specific effects of the tide, waves and possibly also biologically mediated water column stratification and flocculation on (log-transformed) 
non-algal surface SPM by means of statistical models based on simple and multiple regressions.

In a first statistical model (I), surface SPM on day $d$ was evaluated in terms of mean SPM (2003-2009) observed on day $d$ and the tidal coefficient, the latter representing the fortnightly tidal cycle. Model I is expressed as:

$$
\operatorname{SPM}(d, x, y)=\operatorname{SPM}_{\mathrm{M}}(d, x, y)\left(\frac{\operatorname{Tide}(d)}{\operatorname{Tide} 0}\right)^{\alpha(x, y)}
$$

where $\operatorname{SPM}_{\mathrm{M}}(d, x, y)$ is the mean SPM for day $d$ (accounting for seasonal variation) derived from monthly satellite SPM climatologies, Tide $(d)$ is the SHOM tidal coefficient for day $d$, and Tide 0 and $\alpha$ are two unknown parameters estimated by regression after logtransformation of SPM.

In a second statistical model (II), it is hypothesized that $\mathrm{SPM}_{\mathrm{M}}$ can be modelled from waves integrated over a given period. For this purpose, a second variable, Hs50, is introduced which complements the tidal coefficient as an explanatory variable, instead of mean SPM. Hs50 is the Hs integrated over the 50 days preceding day $d$, and is arbitrarily defined as:

$$
\mathrm{Hs} 50(d, x, y)=\frac{\sum_{i=0}^{49} \mathrm{Hs}(d-i, x, y) \times(50-i)}{\sum_{i=0}^{49}(50-i)}
$$

where $\operatorname{Hs}(d-i, x, y)$ is weighted $1 /(i+1)$ for day $d-i$. After testing, a value of 50 days was chosen because this gave the best coefficient of determination at ten locations covering the whole English Channel.

The combined effect of tides and waves was assessed by means of a multiplicative model (linear after log-transformation of non-algal SPM). Model II is expressed as:

$$
\operatorname{SPM}(d, x, y)=a_{0}(x, y)[\operatorname{Tide}(d)]^{\alpha(x, y)}[\operatorname{Hs} 50(d, x, y)]^{\beta(x, y)}
$$

where $a_{0}, \alpha$ and $\beta$ are three unknown parameters estimated after log-transformation of SPM. In a third statistical model (III), mean Chl-a is introduced in order to include seasonal variations in surface SPM. Mean Chl-a concentrations are obtained from satellite climatology. The intention is to account for biologically induced enhancement of flocculation via TEPs (transparent exopolymer particles; Maerz and Wirtz 2009), in turn linked to Chl-a concentration (Claquin et al. 2008). Thus, the settling velocity of aggregates is higher than that of single particles. Surface SPM concentration decreases faster in spring and summer 
when flocculation occurs, accentuating seasonal variability (Ellis et al. 2008). The hypothesis made here is that when Chl-a is present at the surface, flocculation occurs and the water becomes stratified. So, Chl-a is taken as a seasonal indicator of flocculation and water column stratification. Model III is expressed as:

$$
\operatorname{SPM}(d, x, y)=a_{0}(x, y)[\operatorname{Tide}(d)]^{\alpha(x, y)}[\operatorname{Hs} 50(d, x, y)]^{\beta(x, y)}\left[\frac{1}{1+\operatorname{Chl}(d, x, y)}\right]^{\theta(x, y)}
$$

where $\operatorname{Chl}(d, x, y)$ is the mean concentration of Chl-a on day $d$, derived from monthly climatologies, and $a_{0}, \alpha, \beta$ and $\theta$ are four unknown parameters estimated after logtransformation of SPM.

$<$ heading $1>$ Results

$<$ heading2 $>$ Correlograms

Correlograms (spatial resolution of $36 \mathrm{~km}$ ) of SPM time series extracted from raw MODIS data (level 2) over the period 2003-2009 are shown in Fig. 2. The shapes of mean correlograms underline the 14-day spring-neap tidal modulation superimposed on the seasonal cycle.

Using Kmean clustering analysis, four types of correlograms were distinguished depending on the shapes of the autocorrelation functions computed, and particularly the strength of the 14day signature (Fig. 2a). These correspond to water masses with null, low, moderate and strong sensitivity to the spring-neap tidal cycle (Fig. 2, blue, green, yellow and red respectively). Pooling these data to generate a regional map (Fig. 2b) reveals that the Norman-Breton Gulf, the area between the Cotentin Peninsula and the Isle of Wight, the Irish Sea and the western sector of the southern North Sea are characterized by a moderate to strong influence of the tidal cycle. By contrast, the eastern Atlantic Ocean, the eastern southern North Sea and the stratified western English Channel exhibit null to low tidal influence.

$<$ heading2 $>$ Application of statistical models

Statistical models were applied to SPM for the whole English Channel on a 2-pixel grid. For each statistical model and at each location, the unknown parameters were obtained by regression after log-transformation of the 3-year (2007-2009) merged MERIS/MODIS dataset.

Estimated SPM data were compared to satellite-derived SPM, and examples are given for two locations (cf. Fig. 1a) chosen on the basis of the correlogram analysis in Fig. 2b. Location 1 
$\left(4.565^{\circ} \mathrm{W}, 49.76^{\circ} \mathrm{N}\right)$ was at the entrance of the English Channel in the western sector of the the northern Brittany coast near Bréhat Island, where tidal influence is high (Fig. 2b). The results for model I, which includes the tide and mean SPM, are presented in Fig. 3. The strongest correlations between modelled and satellite-derived SPM values are found at locations detected by the correlogram analysis as being strongly influenced by the tide-for instance, location 2 (Fig. 3b), where the coefficient of determination $r^{2}$ is 0.3 . At location 1 , by contrast, identified as being weakly influenced by the tide, the correlation is markedly weaker (Fig. 3a; $\mathrm{r}^{2}<0.02$ ). It is noticeable that the frequent occurrence of coccolithophores in summer at the entrance of the English Channel -disturbs" the mean SPM trend in July (Fig. 1c) and August at location 1 (Fig. 3a), with an increase of SPM in summer. The coefficient of determination indicates the part of the variance in the SPM time series explained by the tide (Fig. 3c). The $r^{2}$ map shows patterns similar to those displayed on the map obtained from the correlogram analysis (Fig. 2b). Highest $r^{2}$ values are found in areas where the correlogram analysis identified the strongest tidal impact on surface SPM. Thus, mapping of $\mathrm{r}^{2}$ computed every four pixels yields an additional classification of the sensitivity of near-free surface SPM to the tide in the English Channel. Consideration of the wave effect as forcing parameter has a noticeable influence on model performance (Fig. 4). Model II, in which seasonal SPM is replaced by weighted wave height, better explains the variability in SPM concentration in areas where the tide was shown to have little influence (location 1, Fig. 4a). In areas dominated by the tide—-for instance, at location 2 (Fig. 4b) - the results are still good with correct estimation of SPM variability related to waves. This model improves the correlation between prediction and satellite observation for the whole English Channel (Fig. 4c), and particularly in the western sector and off Brighton where $\mathrm{r}^{2}$ values reach 0.6 . However, SPM concentration is systematically overestimated during summer, and underestimated in the case of very strong waves (Fig. 4a, b). Statistical model III had Chl-a as an explanatory variable in an attempt to accentuate seasonality; this would at least partially correct for this summer overestimation. Indeed, this step improves the correlation between observed and modelled data, especially in summer (Fig. 5a, b) when the lag between satellite-derived SPM (blue line) and SPM estimated using model III (red line) decreases. Improvement of $\mathrm{r}^{2}$ is particularly evident at the entrance of the English Channel, with values increasing from about 0.6 (Fig. 4c) to about 0.7 (Fig. 5c). 
$<$ heading2 $>$ Impact of specific variables

Results for the correlogram analysis and model I highlight areas where the neap-spring influence on surface SPM concentration is particularly high. As expected, these are areas experiencing a large tidal range and/or strong tidal currents (SHOM 2000).

Based on site-specific $r^{2}$ values obtained by application of model I (Fig. 3c), areas with different degrees of correlation between tides and SPM concentration may be distinguished more precisely. In general, the correlation in the central and eastern English Channel is higher than in the western sector, except in the Norman-Breton Gulf and along the Brittany coast. The eastern English Channel is protected from waves coming from the west by the Cotentin Peninsula and, even if the tidal currents are not particularly strong in the area as a whole, they appear to be the dominant phenomenon driving SPM dynamics. The very significant tidal range in the Norman-Breton Gulf explains the strong link between the tide and SPM in this region. Higher $\mathrm{r}^{2}$ values can also be detected locally, corresponding to areas characterized by strong tidal currents (SHOM 2000; Guillou 2007) — for instance, the Pays de Caux, the Cotentin, Saint-Brieuc Bay and the Ushant front. All these areas have surface SPM concentration varying in tight coupling with turbulence generated by the tide, and are characterized by well mixed waters (Pingree and Griffiths 1978). The improved estimation of SPM in the entrance of the English Channel obtained after introducing the effects of waves in model II highlights the strong influence of this physical parameter in this area (Fig. 4). The highest $r^{2}$ values are observed in areas most exposed to waves: the entrance to the English Channel, the Norman-Breton Gulf, off the coast of Brighton and along the coasts of the southern North Sea. The former three areas are exposed to waves coming from the west (main direction in the English Channel; Météo-France 1991). These waters are mixed only part of the year (Pingree and Griffiths 1978), and stratification may limit the resuspension of SPM as it reduces vertical mixing and hinders the transmission of stirring from the surface to the bottom layer (Bowers 2003). Together with TEP-mediated particle aggregation, there is a tight coupling between water column stratification and Chl-a dynamics. For instance, stratification sets up gradually from west to east at the entrance of the English Channel from late spring to mid-summer when large blooms of phytoplankton are common, often with high abundance of Karenia mikimotoi, a toxic dinoflagellate visible from space (Vanhoutte-Brunier et al. 2008). Indeed, the results of the present study convincingly demonstrate that introducing Chl-a as model parameter (model III) measurably improves predictive power. Note that other variables such as sea surface temperature could have been chosen instead for that purpose, as confirmed by tests (data not shown). Thus, adding Chl-a or 
sea surface temperature as variable in the model allows seasonal variations in SPM to be better predicted.

$<$ heading2 $>$ Estimation of SPM at a regional scale

In early spring with medium-sized waves, model III gives good estimations of SPM dynamics in the English Channel (Fig. 6a-c). The pattern predicted for the 21 March 2007 (Fig. 6a) is similar to that observed in the interpolated SPM image (Fig. 6b) and in the raw SPM image (Fig. 6c). As expected, estimated SPM concentrations are high around the Isle of Wight and in the Norman-Breton Gulf, and show intermediate values in the central and western Channel sectors.

During the summer, however, and even if overall model III performance remains good, there tends to be an overestimation of SPM (Fig. 6d-f) mainly in the eastern English Channel where observed values are low. The remote-sensing algorithm used for estimating SPM may fail at low concentrations (less than about $1 \mathrm{~g} / \mathrm{m}^{3}$; Gohin et al. 2005) and/or the problem may be inherent to the statistical modelling exercise as such.

Particularly high SPM concentrations were observed 2 days after a storm of 9 December 2007 (Fig. 6h, i), well above typical mean winter values (Fig. 1a). The Hurd Deep had distinctly lower concentrations. As with any model, statistical model III is not able to fully predict the effects of such extreme events (Fig. 6g). Performance was good for the eastern English Channel and the Norman-Breton Gulf, classified as being strongly influenced by tidal activity. In the western Channel where wave influence was shown to be significant, however, SPM concentrations are clearly underestimated, except in the vicinity of the Hurd Deep.

\section{$<$ heading2 $>$ Limitations of satellite-derived SPM}

Processing of satellite reflectance data to estimate non-algal SPM incorporates several assumptions. Notably, it is assumed that the inherent optical properties of particles remain essentially the same throughout the processed area. For example, the relation between the backscattering coefficient and SPM concentration is taken to be linear, whatever the size and composition of the particles. This means that the specific backscattering coefficient (backscattering coefficient by unit mass) is set as constant for a given study area. This oversimplifies conditions in the English Channel, where the specific scattering coefficient could be higher at sites of maximum hydrodynamic energy and during spring tides (Bowers and Binding 2006). Indeed, Lubac and Loisel (2007) have highlighted the effect of the particulate backscattering ratio (backscattering to scattering ratio) on marine reflectance in the 
eastern English Channel, and thus the sensitivity of the latter to particle aggregation. Changes in turbulence lead to particles alternatively aggregating through flocculation during calm weather, and disaggregating during storms and at spring tide. Thereby, the size, density and shape of particles change, inducing variations in the specific backscattering coefficient. In the present case, it would have been better to use maps of backscattering coefficients but these products are not provided as daily interpolated images. Despite limitations resulting from such approximations in satellite data processing, the nature and intensity of some key environmental factors (waves and tides) driving variability in surface turbidity have been accounted for in this study.

\section{$<$ heading2 $>$ Limitations of statistical models I-III}

Bathymetry as such was not incorporated as explanatory variable in the statistical models IIII. However, the unknown parameters were calculated for each location. Therefore, the influence of bathymetry, which is constant in time, has been included in these parameters. In this study, tidal influence was assessed only in terms of the neap-spring cycle but the semidiurnal cycle also contributes significantly to resuspension processes in this study region characterized by strong tides (Lafite et al. 2000). In contrast to other, longstanding studies dealing with short-term site-specific SPM variability (e.g. Pejrup 1986; Weeks et al. 1993), in the present case it was not possible to account for semi-diurnal tidal influence because the time of satellite data acquisition is not known precisely enough and two acquisitions per day do not allow to investigate the daily cycle. MERIS and MODIS have sun-synchronous orbits: MERIS crosses the equator every day at about 10:30 a.m. and MODIS at about 1:30 p.m. The repeat cycles are 35 and 16 days for MERIS and MODIS respectively. For instance, the observation time of raw MODIS images varies between about 11:00 a.m. and 2:00 p.m. in the English Channel (east or west swath is automatically chosen depending on the zenithal view angle). This irregular sampling interval likely leads to aliasing of data, making it difficult to determine the relative importance of the neap-spring and semi-diurnal tidal cycles as drivers of SPM dynamics.

For the merged MERIS/MODIS product, a time lag of about $5 \mathrm{~h}$ is possible with acquisition between about 9:00 a.m. and 2:00 p.m. Therefore, different situations would be encountered during the semi-diurnal tidal cycle. Moreover, the interpolation scheme used for generating the merged database can use images separated by \pm 5 days from the interpolated day, depending on cloud coverage. Despite limitations due to spatial and temporal interpolation 
effects, the ca. 14-day signature of the neap-spring tidal cycle has been clearly identified from the interpolated images (Fig. 3a, b).

The negative interpolation effect is more serious for the sensitivity of modelled SPM to waves. In the case of persistent cloudy skies on days preceding a storm, signs of the storm may be construed in the daily interpolated SPM field already 5 days before the event actually occurs. At the opposite extreme, the storm described above occurred on the 9th December 2007 and the closest image with a relatively clear sky is dated the 11th December (Fig. 6i). Image interpolation for calibrating model III leads to a maximum SPM signature on 11th December, i.e. 2 days after the storm. Evidently, extreme events cannot be precisely located in time, which may explain the relatively low sensitivity of the model to strong waves. The effect of waves is represented by the Hs50 parameter, this being the weighted average of the significant wave height over the preceding 50 days. The results (not shown) obtained with a classical average of Hs over the same 50-day period were not significantly different. Currently, the same approach is being followed in work in the Bay of Biscay, where tests suggest that a period of 25 days is more appropriate (Gohin, unpublished data). Exposure of the Bay of Biscay shelf to oceanic storms leads to a short, strong immediate effect on SPM resuspension by waves. In order to increase model sensitivity to waves, it would be possible to better define the weights attributed to wave activity preceding the estimated day by using raw MODIS or MERIS data, accepting data gaps in the time series. In this case, the satellite SPM signature could be attributed to a precise day and fitting the model to those data would be easier, despite a smaller dataset. Nevertheless, the overall role of the tide and waves in this study of the English Channel has been investigated sufficiently well to obtain qualitative information on surface SPM variability useful for development of a new hydro-sedimentary model.

In addition to surface gravity waves, winds may generate near-surface turbulent currents, depending mainly on their strength and duration. In turn, this leads to the formation of the well-known Ekman layer, which is about $20 \mathrm{~m}$ thick in the English Channel (Garreau 1997). By implication, wind-driven currents alone are not responsible for bottom sediment resuspension in this environment. In addition to tide-induced turbulence kinetic energy (TKE), their associated TKE can nevertheless contribute to maintaining particulate matter in suspension, as pointed out by Bowers (2003). For simplicity, this impact has not been taken into account in the different statistical models tested here, the wind effect being considered only in terms of waves. 
In the present study, the tide is represented by a spatially uniform variable: the tidal English Channel, linked mainly with the bathymetry and the shape of the coastlines. This may also explain the discrepancy observed in the central English Channel, especially along the Wight-Cotentin cross-section where Velegrakis et al. (1997) noted that SPM variation appears to be strongly controlled by enhanced advection. Determining the relevant variable to deal with this aspect in a simple statistical model is not straightforward and deserves further research.

Arguably the most tenuous premise in the present modelling exercise was that mean seasonal Chl-a concentration could serve as proxy for water column stratification and particle flocculation. In fact, seasonal Chl-a evolution estimated by remote sensing in turbid coastal waters is well represented with the algorithm used here (Gohin 2011), and adding Chl-a improves the coefficient of determination and, therefore, SPM predictions. This does not imply a causal relationship between Chl-a and surface SPM, but rather that non-algal SPM and the inverse of Chl-a can evolve seasonally in similar ways. Sea surface temperature shows promise as another suitable proxy.

$<$ heading $1>$ Conclusions

This study aimed to assess non-algal SPM variability in the English Channel based only on satellite images. Three statistical models were tested with different physical variables. Tide and waves were identified as important factors in controlling surface SPM. The roles of water column stratification and particle flocculation need confirmation. The main findings of the present study are the following:

1. A strong dependency on the neap-spring cycle was identified for the central and eastern English Channel, the Norman-Breton Gulf and the Brittany coast.

2. Modelling shows a strong dependency on integrated Hs in the western part of the English Channel.

3. Considering the simplicity of the formulation, surface SPM concentrations predicted by model III (SPM versus tide, waves and Chl-a) correlated well with observed values $\left(r^{2}>0.5\right.$ in the western Channel). Except in the case of storms, the model faithfully reproduces SPM patterns and intensity.

The quality of the predictions was not homogeneous over the whole study area, and the poorest simulations were obtained in the eastern sector where hydrodynamic conditions are more complex and advection is important. The choice of a limited number of simple 
explanatory variables and spatiotemporal interpolation in SPM datasets (inducing uncertainty in the SPM fields) limit the performance of statistical models. It should be possible to further improve model performance by incorporating new explanatory variables (e.g. wind from satellite scatterometers) and/or by using higher-resolution raw data to reduce smoothing due to interpolation. The results of the present study are being integrated into the numerical model currently under development, the ultimate aim being to represent more complex hydrodynamic configurations encompassing the whole water column at higher spatial and temporal precision.

\section{Acknowledgements}

The authors are grateful to the MyOcean (European Commission) project and the Space Agencies for providing ocean colour data from MODIS (NASA) and MERIS (ESA), and to the IOWAGA (European Commission) and PREVIMER (French National Pilot Project of Coastal Oceanography) projects for providing wave data. The raw MODIS data were provided by the MarCoast2 project (ESA). This paper is also a contribution to the CHannel integrated Approach for marine Resource Management (CHARM) Phase 3 project (INTERREG IV A France (Channel) - England cross-border European cooperation programme, co-financed by the European Regional Development Fund). David Bowers (Bangor University, UK) is warmly thanked for his help in reading and improving the final manuscript. Quinten Vanhellemont (Management Unit of the North Sea Mathematical Models, Belgium) is acknowledged for providing satellite products generated by the algorithm of B. Nechad and colleagues. The authors acknowledge constructive assessments by two anonymous reviewers.

\section{References}

Ardhuin F, Rogers E, Babanin AV, Filipot J, Magne R, Roland A, van der Westhuysen A, Queffeulou P, Lefevre JM, Aouf L, Collard F (2010) Semiempirical dissipation source functions for ocean waves. Part I: Definition, calibration, and validation. J Phys Oceanogr 40(9):1917-1941

Babin M, Morel A, Fournier-Sicre V, Fell F, Stramski D (2003) Light scattering properties of marine particles in coastal and open ocean waters as related to the particle mass concentration. Limnol Oceanogr 48(2):843-859

Bow S (1984) Pattern recognition. M. Dekker, New York 
Bowers DG (2003) A simple turbulent energy-based model of fine sediments in the Irish Sea.

Cont Shelf Res 23:1495-1505

Bowers DG, Binding CE (2006) The optical properties of mineral suspended particles: a review and synthesis. Estuar Coastal Shelf Sci 67(1/2):219-230.

doi:10.1016/j.ecss.2005.11.010

Bowers DG, Boudjelas S, Marker GEL (1998) The distribution of fine suspended sediments in the surface waters of the Irish Sea and its relation to tidal stirring. Int J Remote Sensing 19(14):2789-2805

Claquin P, Probert I, Lefebvre S, Veron B (2008) Effects of temperature on photosynthetic parameters and TEP production in eight species of marine microalgae. Aquat Microbial Ecol 51(1):1-11. doi:10.3354/ame01187

Ellis KM, Binding CE, Bowers DG, Jones SE, Simpson JH (2008) A model of turbidity maximum maintenance in the Irish Sea. Estuar Coastal Shelf Sci 76(4):765-774. doi:10.1016/j.ecss.2007.08.020

Garreau P (1997) Caractéristiques hydrodynamiques de la Manche. Oceanis 23(1):65-88 Gohin F (2011) Annual cycles of chlorophyll-a, non-algal suspended particulate matter and turbidity observed from space and in-situ in coastal waters. Ocean Sci 7:705-732. doi:10.5194/os-7-705-2011

Gohin F, Druon JN, Lampert L (2002) A five channel chlorophyll concentration algorithm applied to SeaWiFS data processed by Seadas in coastal waters. Int J Remote Sensing 23:1639-1661

Gohin F, Loyer S, Lunven M, Labry C, Froidefond JM, Delmas D, Huret M, Herbland A (2005) Satellite-derived parameters for biological modelling in coastal waters: illustration over the eastern continental shelf of the Bay of Biscay. Remote Sensing Environ 95(1):29-46 Guillou N (2007) Rôles de l'hétérogénéité des sédiments de fond et des interactions houlecourant sur l'hydrodynamique et la dynamique sédimentaire en zone subtidale - applications en Manche orientale et à la pointe de la Bretagne. PhD Thesis, Université de Bretagne Occidentale, Brest

Hammer Ø, Harper DAT, Ryan PD (2001) PAST: Paleontological Statistics software package for education and data analysis. Paleontologia Electronica 4(1):1-9

Huret M, Gohin F, Delmas D, Lunven M, Garcon V (2007) Use of SeaWiFS data for light availability and parameter estimation of a phytoplankton production model of the Bay of Biscay. J Mar Systems 65(1/4):509-531 
Lafite R, Shimwell S, Grochowski N, Dupont J-P, Nash L, Salomon J-C, Cabioch L, Collins

M, Gao S (2000) Suspended particulate matter fluxes through the Straits of Dover, English Channel: observations and modelling. Oceanol Acta 23(6):687-700

Lubac B, Loisel H (2007) Variability and classification of remote sensing reflectance spectra in the eastern English Channel and southern North Sea. Remote Sensing Environ 110:45-58 Maerz J, Wirtz K (2009) Resolving physically and biologically driven suspended particulate matter dynamics in a tidal basin with a distribution-based model. Estuar Coastal Shelf Sci 84(1):128-138. doi:10.1016/j.ecss.2009.05.015

Ménesguen A, Gohin F (2006) Observation and modelling of natural retention structures in the English Channel. J Mar Systems 63(3/4):244-256

Météo-France (1991) Données et statistiques n¹1, zones inter services mer, tome 1, Manche et Atlantique. Direction de la météorologie nationale, service central exploitation, Paris Nechad B, Ruddick KG, Park Y (2010) Calibration and validation of a generic multisensor algorithm for mapping of total suspended matter in turbid waters. Remote Sensing Environ 114:854-866

Neukermans G, Ruddick K, Bernard E, Ramon D, Nechad B, Deschamps PY (2009) Mapping total suspended matter from geostationary satellites: a feasibility study with SEVIRI in the Southern North Sea. Optics Express 17(16):14029-14052

Pejrup M (1986) Parameters affecting fine-grained suspended sediment concentrations in a shallow micro-tidal estuary, Ho-Bugt, Denmark. Estuar Coastal Shelf Sci 22:241-254 Petus C, Chust G, Gohin F, Doxaran D, Froidefond J, Sagarminaga Y (2010) Estimating turbidity and total suspended matter in the Adour River plume (South Bay of Biscay) using MODIS 250-m imagery. Cont Shelf Res 30(5):379-392

Pingree RD, Griffiths DK (1978) Tidal fronts on the shelf seas around the British Isles. J Geophys Res 83:4165-4622

Salomon JC, Breton M (1993) An atlas of long-term currents in the Channel. Oceanol Acta 16(5/6):439-448

Saulquin B, Gohin F, Garrello R (2011) Regional objective analysis for merging highresolution MERIS, MODIS/Aqua, and SeaWiFS chlorophyll-a data from 1998 to 2008 on the European Atlantic shelf. IEEE Trans Geosci Remote Sensing 49(1):143-154

SHOM (2000) Courants de marée et hauteurs d'eau. La Manche de Dunkerque à Brest. Service Hydrographique et Océanographique de la Marine, Brest, Rapport 564-UJA Tolman HL (2008) A mosaic approach to wind wave modeling. Ocean Modell 25(1/2):35-47 
van der Molen J, Bolding K, Greenwood N, Mills DK (2009) A 1-D vertical multiple grain size model of suspended particulate matter in combined currents and waves in shelf seas. $\mathrm{J}$ Geophys Res 114:F01030. doi:10.1029/2008JF001150

Vanhoutte-Brunier A, Fernand L, Ménesguen A, Lyons S, Gohin F, Cugier P (2008)

Modelling the Karenia mikimotoi bloom that occurred in the western English Channel during summer 2003. Ecol Modell 210(4):351-376

Velegrakis AF, Gao S, Lafite R, Dupont JP, Huault MF, Nash LA, Collins MB (1997)

Resuspension and advection processes affecting suspended particulate matter concentrations in the central English Channel. J Sea Res 38(1/2):17-34

Velegrakis AF, Michel D, Collins MB, Lafite R, Oikonomou EK, Dupont JP, Huault MF, Lecouturier M, Salomon JC, Bishop C (1999) Sources, sinks and resuspension of suspended particulate matter in the eastern English Channel. Cont Shelf Res 19(15/16):1933-1957 Weeks AR, Simpson JH, Bowers D (1993) The relationship between concentrations of suspended particulate material and tidal processes in the Irish sea. Cont Shelf Res 13(12):1325-1334

Fig. 1 Monthly averaged non-algal SPM concentration (dry mass basis) maps for the English Channel over the period 2003-2009: a winter (January), b spring (April), c summer (July) and d autumn (October)

Fig. 2 a Classification of correlograms in terms of their shapes (black lines all correlograms of a given class, coloured lines mean correlograms) and $\mathbf{b}$ resulting map of four classes of neap-spring cycle influence on surface SPM: red strong, yellow moderate, green low, blue no influence

Fig. 3 Time series of satellite-derived non-algal SPM (blue lines), SPM estimated using model I (red lines), mean non-algal SPM (green lines) and tidal coefficients (dotted lines) at a location 1 and $\mathbf{b}$ location 2. $\mathbf{c}$ Map of $\mathrm{r}^{2}$ values obtained with model I for the English Channel Fig. 4 Time series of satellite-derived non-algal SPM (blue lines), SPM estimated using model II (red lines) and Hs50 (green lines) at a location 1 and b location 2. $\mathbf{c}$ Map of $\mathrm{r}^{2}$ values obtained with model II for the English Channel

Fig. 5 Time series of satellite-derived non-algal SPM (blue lines), SPM estimated using model III (red lines) and Hs50 (green lines) at a location 1 and b location 2. $\mathbf{c}$ Map of $\mathrm{r}^{2}$ values obtained with model III for the English Channel 
Fig. 6 Comparison of non-algal SPM estimated by model III (a, d, g), and observed on kriged

1 remote-sensing images $(\mathbf{b}, \mathbf{e}, \mathbf{h})$ and raw remote-sensing images $(\mathbf{c}, \mathbf{f}, \mathbf{i})$ of 21 March, 30 July and 11 December 2007 respectively 


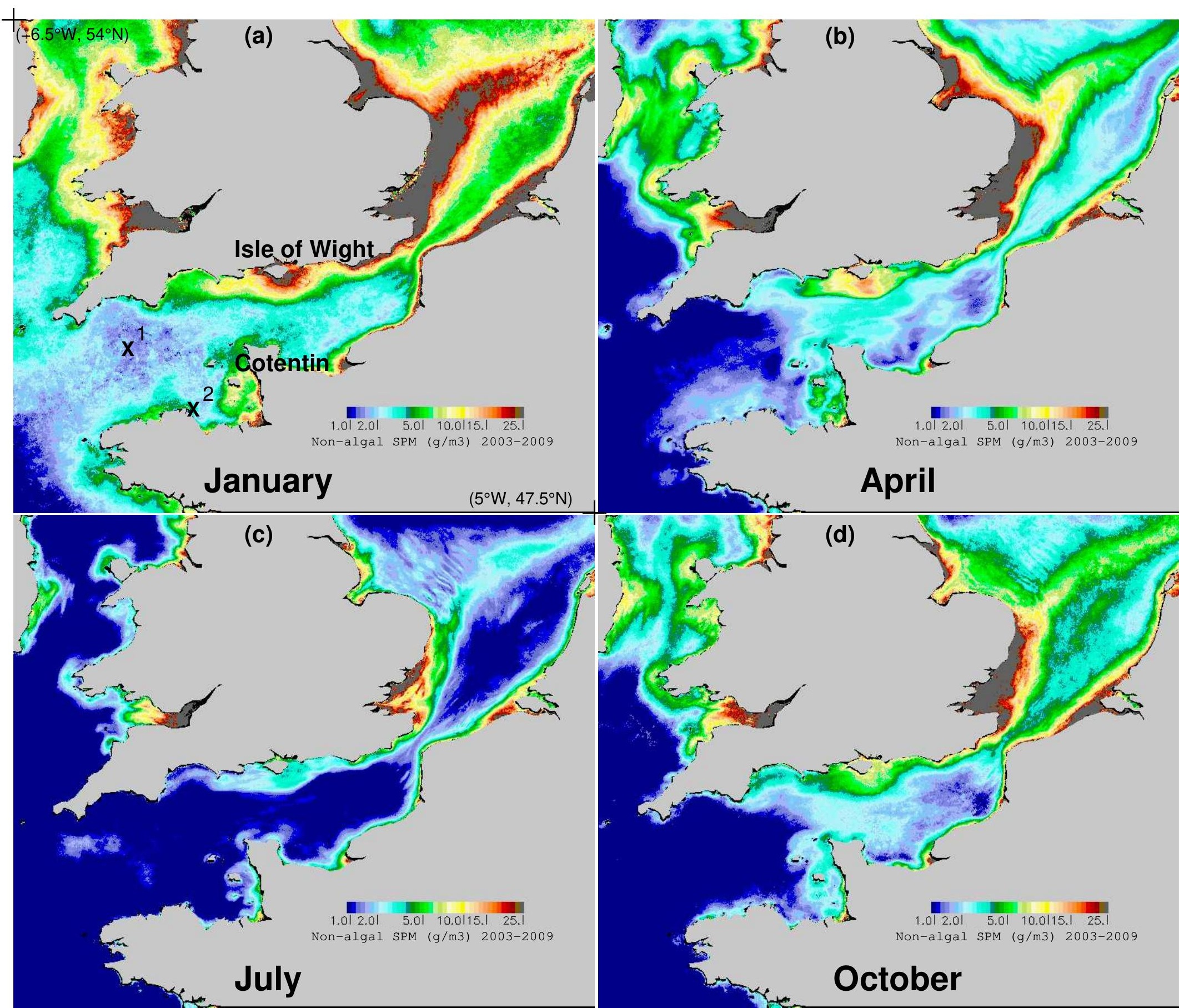


(a)
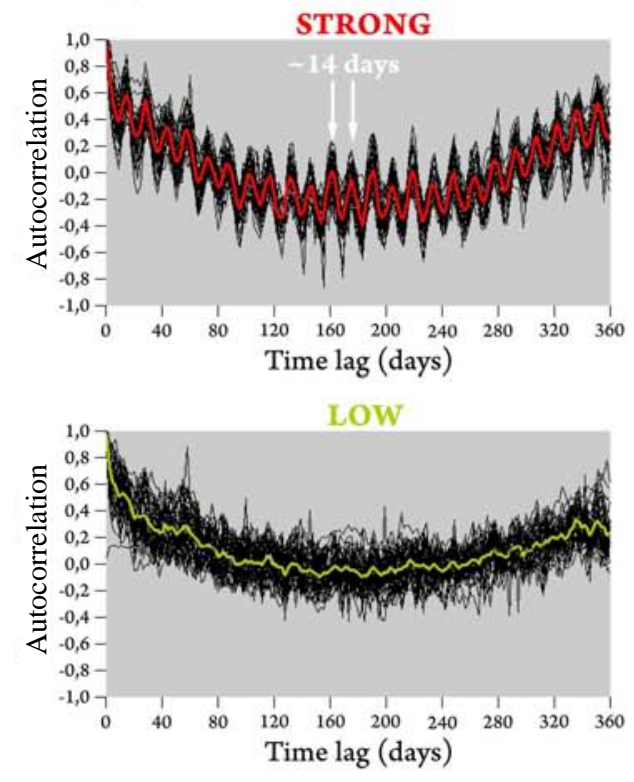

(b)
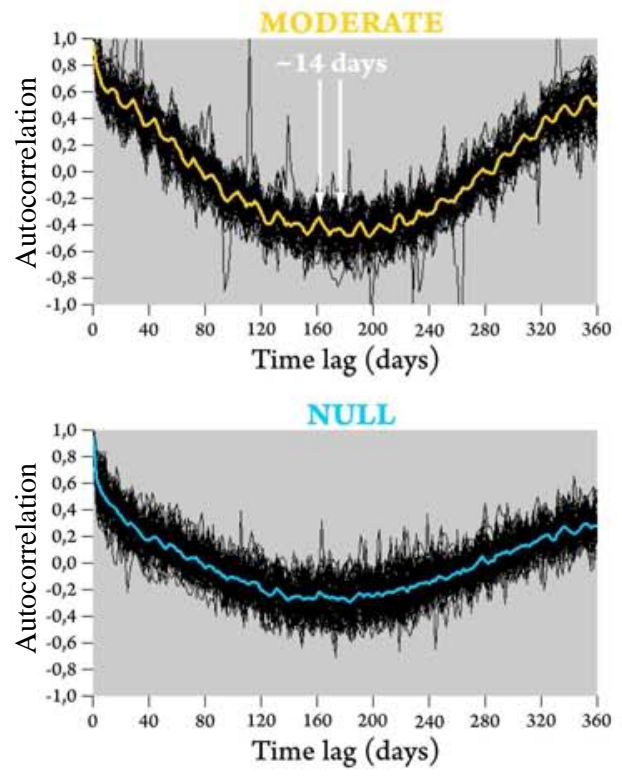

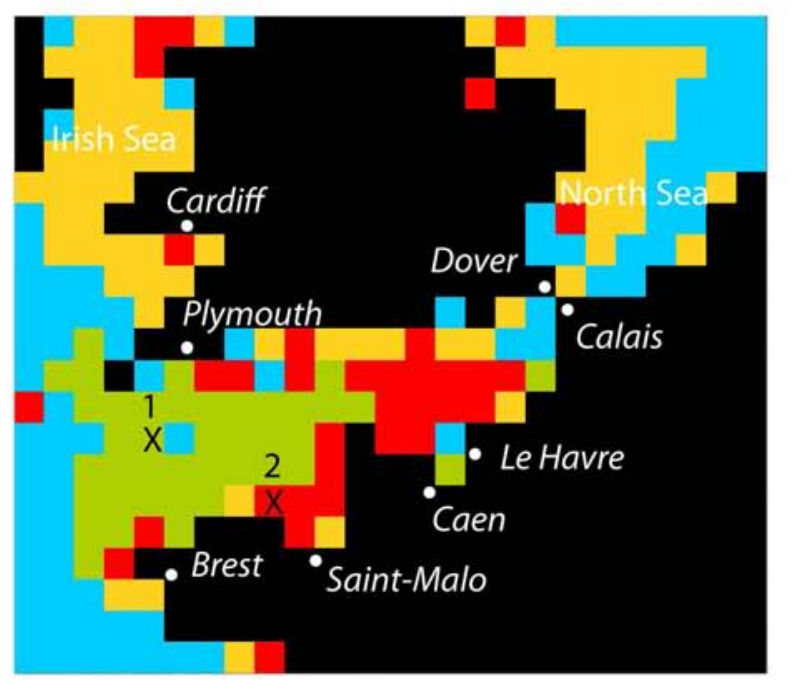




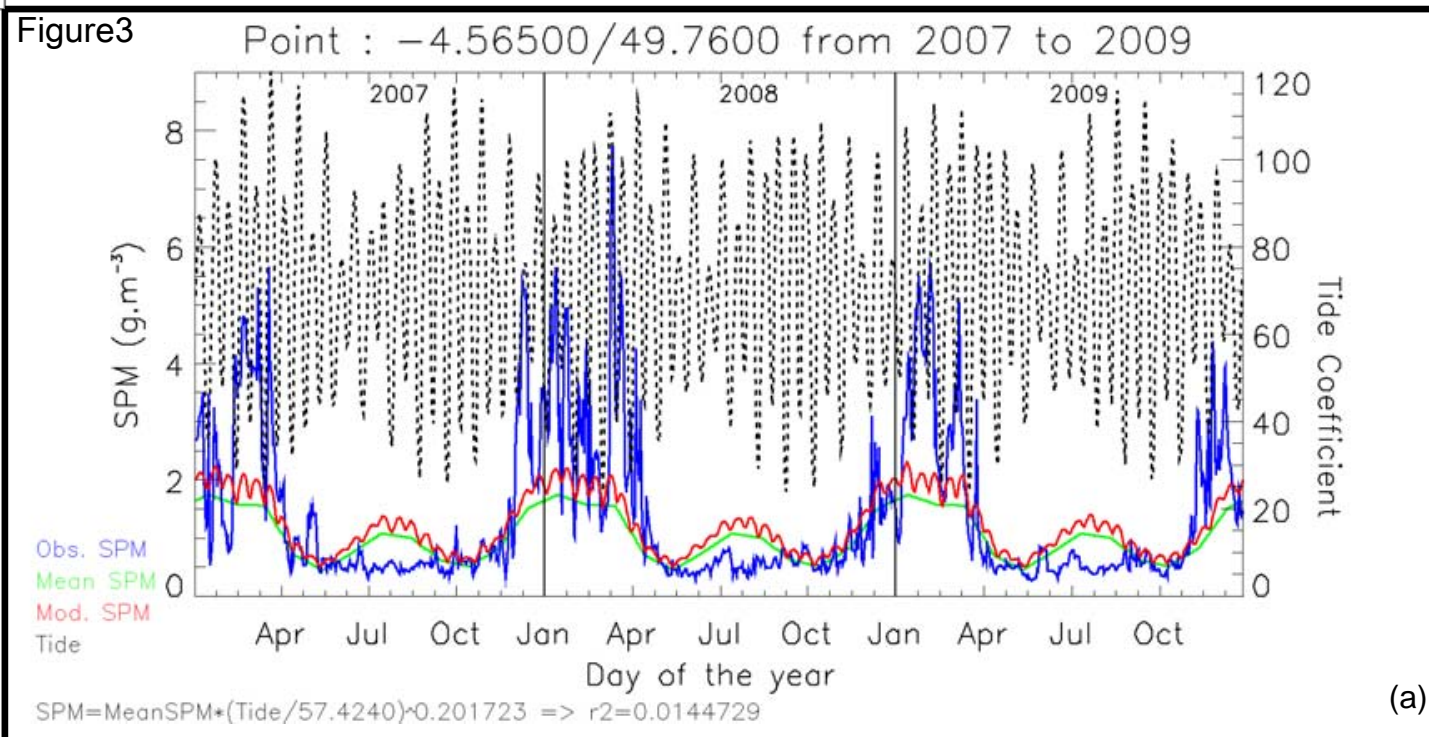

Point : $-2.91500 / 48.9800$ from 2007 to 2009

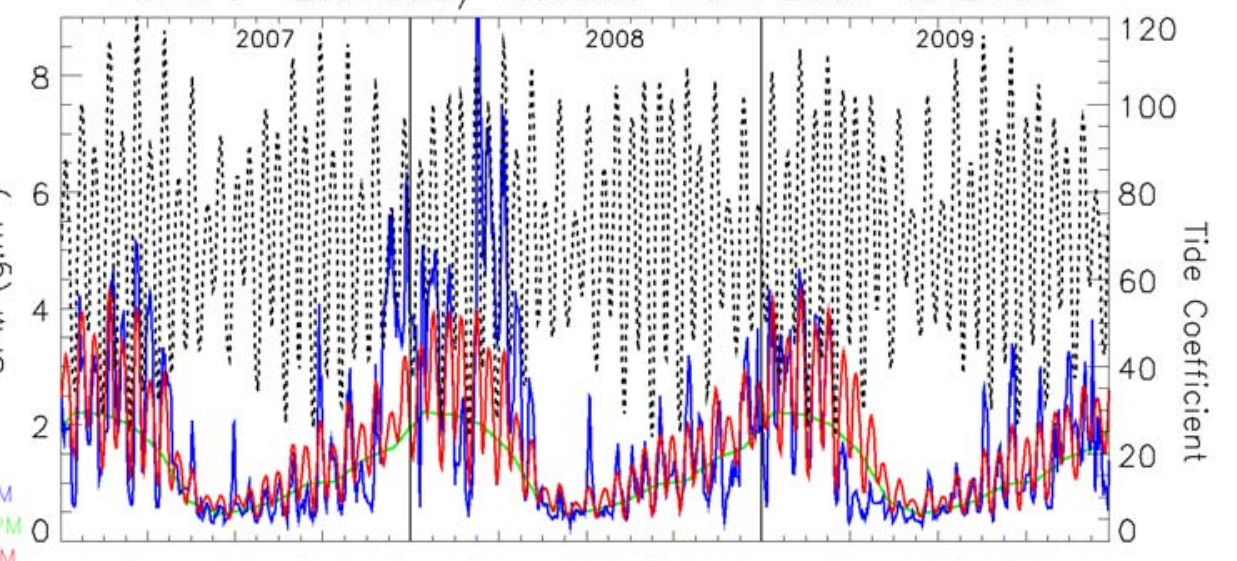

Apr Jul Oct Jan Apr Jul Oct Jan Apr Jul Oct Day of the year

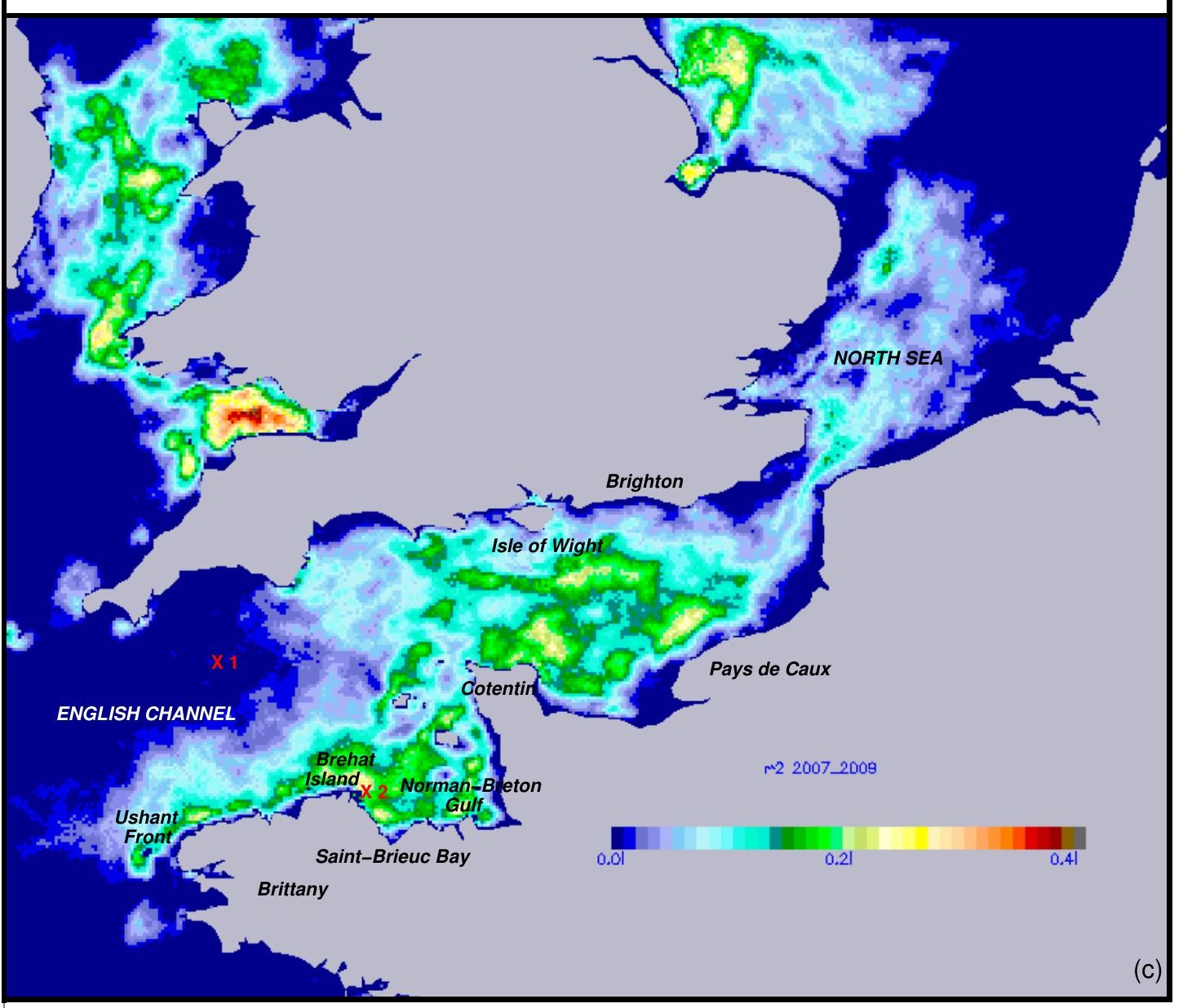


Figure4

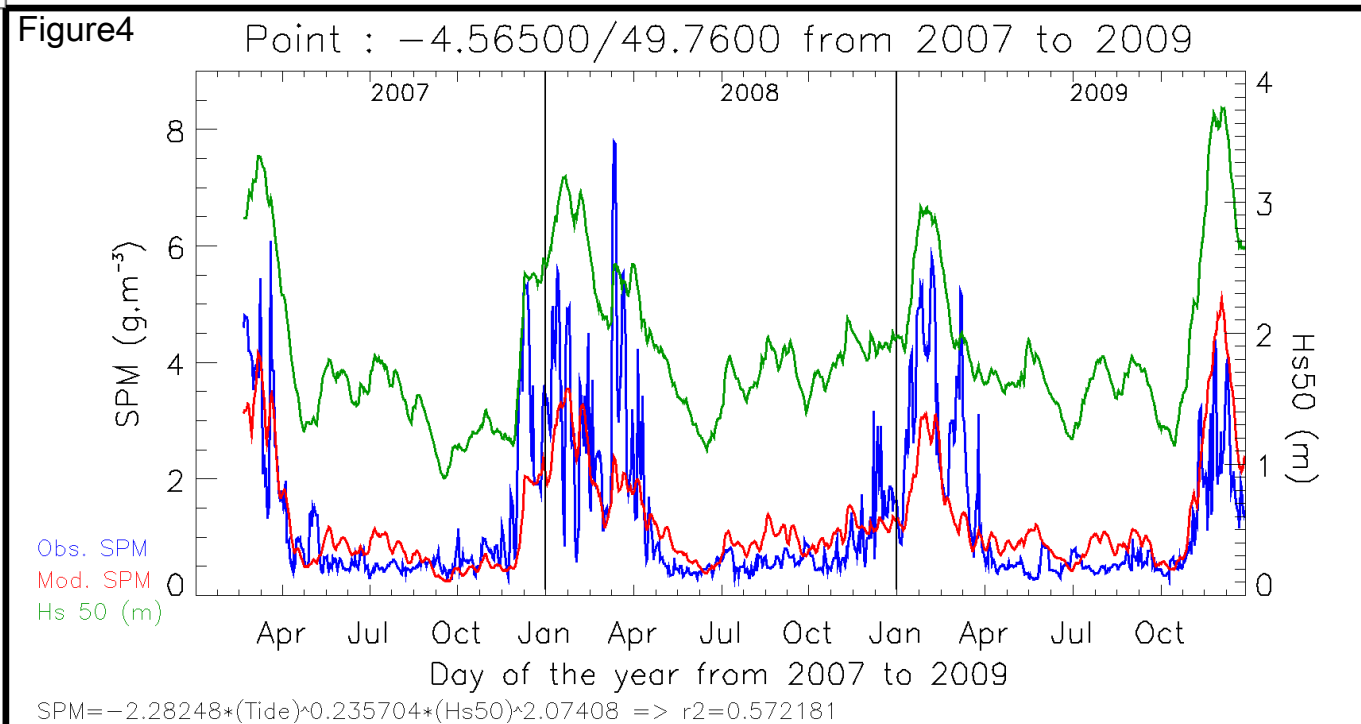

Point : $-2.91500 / 48.9800$ from 2007 to 2009
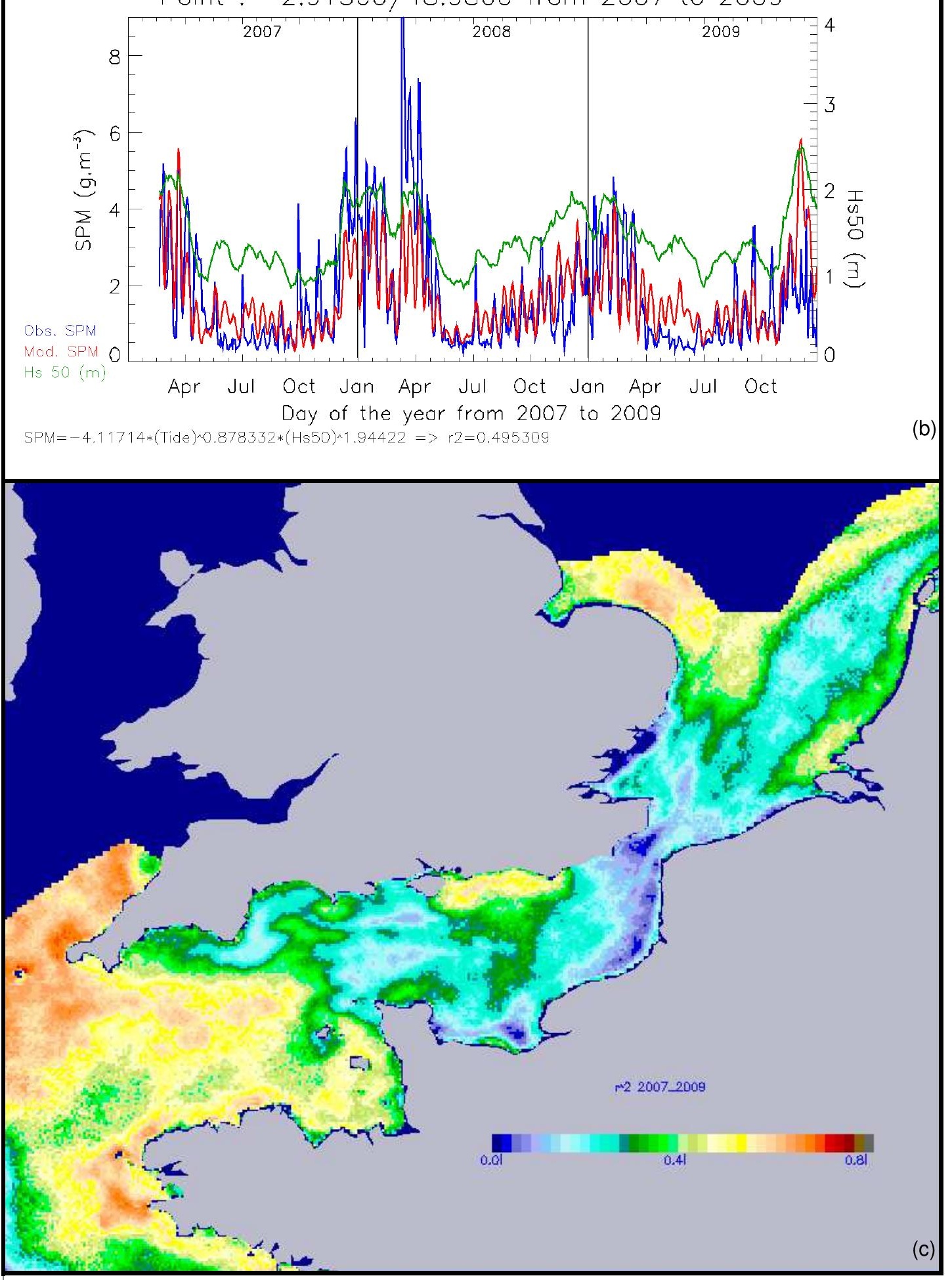


Figure5

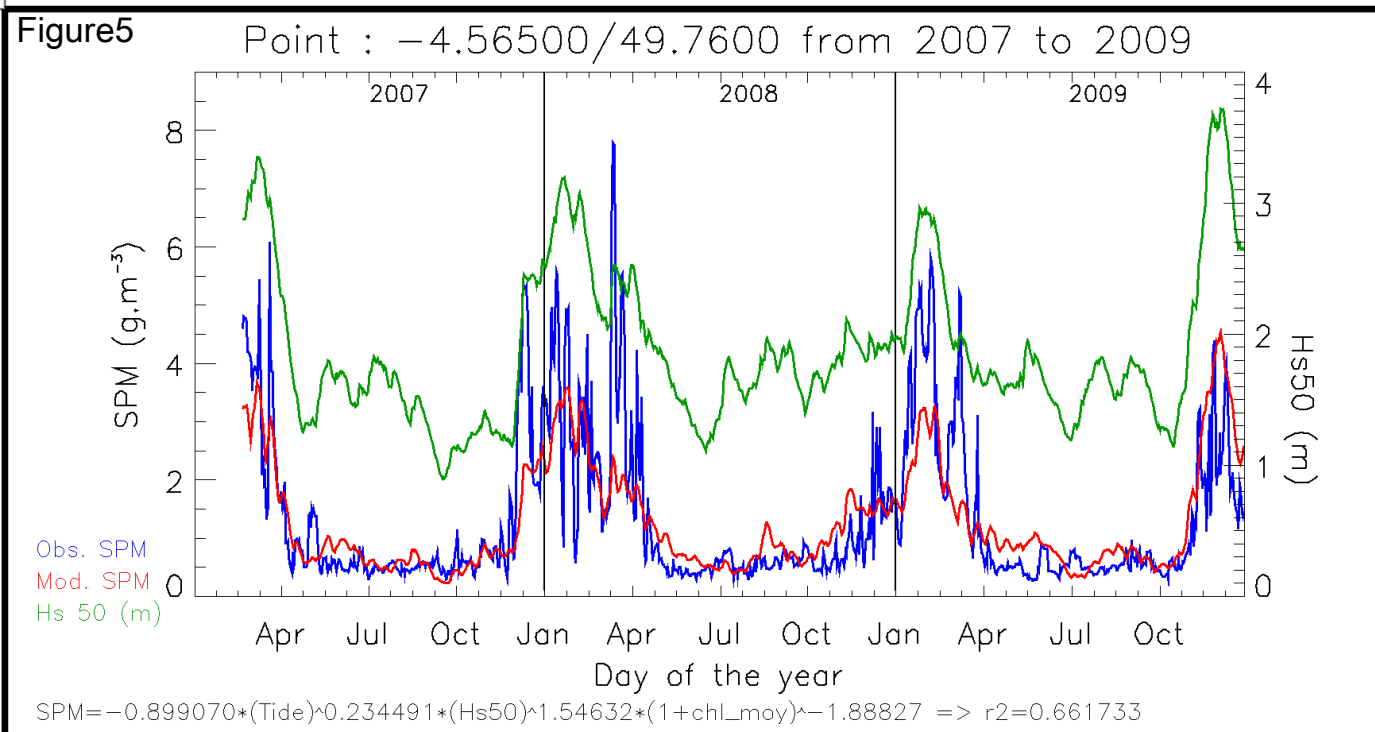

Point : $-2.91500 / 48.9800$ from 2007 to 2009
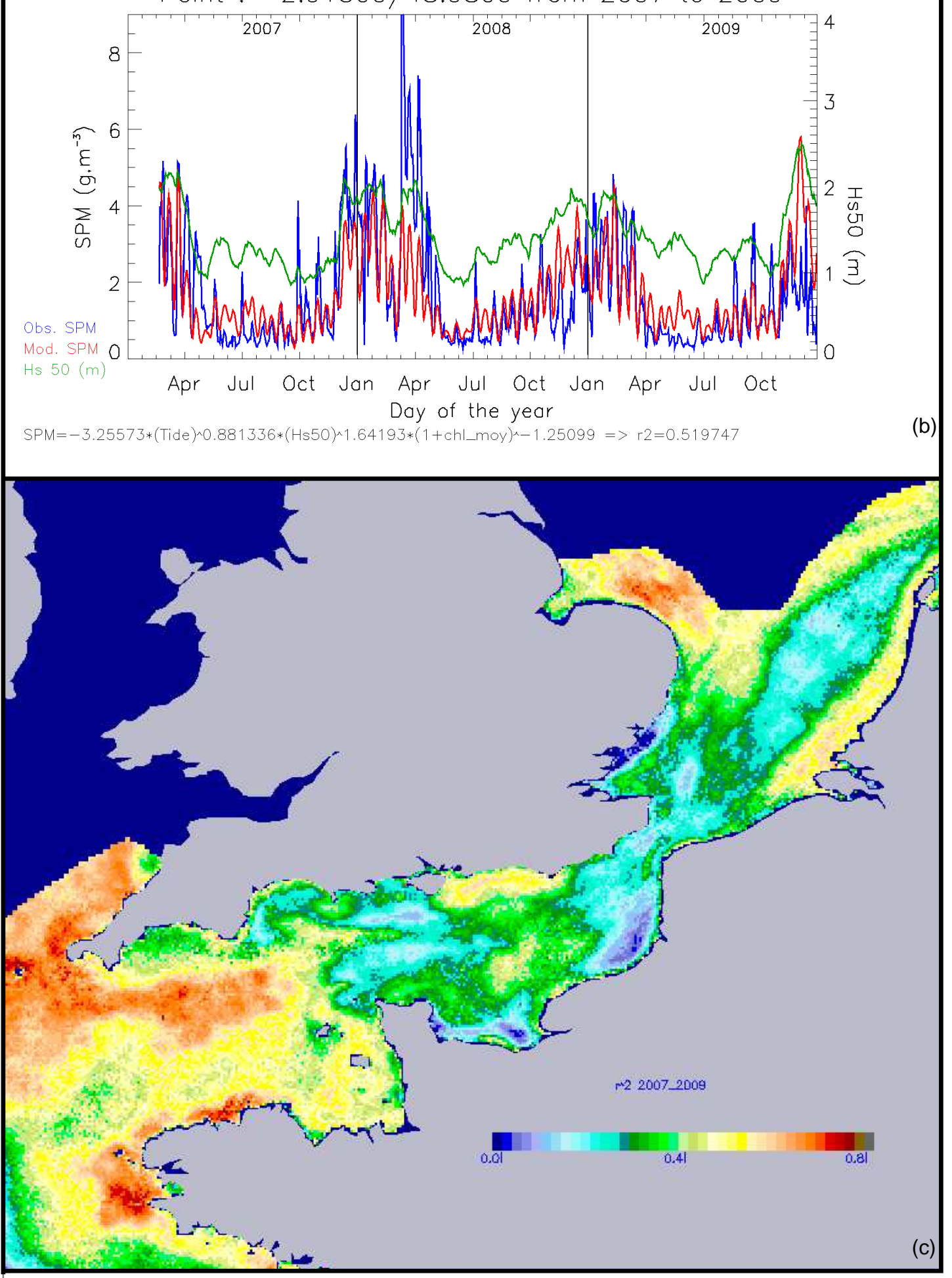
